Leyva César, M. y Arriaga Ornelas, J.L. La defensa del territorio de San Franciso Xochicuauutla, México, como una forma contenciosa de la diferencia. Derecho y Ciencias Sociales. Noviembre 2019 - Abril 2020 N $^{\circ} 22$. Pgs 144 - 166. ISNN 1852-2971 Instituto de Cultura

Jurídica y Maestría en Sociología Jurídica. FCJ y S. UNLP

\title{
La defensa del territorio en San Francisco Xochicuautla, México, como una forma contenciosa de la diferencia
}

The defense of the territory in San Francisco Xochicuautla, Mexico, as a contentious form of the difference

\author{
Mario Leyva César \\ José Luis Arriaga Ornelas“•
}

\section{Resumen}

El presente texto es resultado de un trabajo de antropología jurídica sobre el conflicto entre el Estado mexicano y la comunidad de San Francisco Xochicuautla, Lerma, Estado de México, a raíz de un proyecto carretero. Se explora el planteamiento hipotético de que dicho conflicto se eslabona a una histórica cadena de procesos jurídicos que no han resuelto de modo definitivo la presencia de los pueblos indígenas dentro del Estado mexicano. Se expone como planteamiento central que el sistema jurídico mexicano actual y las prácticas políticas de sus gobernantes, articuladas con el capital interno y extranjero, forman parte de un contexto jurídico-político en el que se presentan episodios que vuelven visibles algunas "formas contenciosas de la diferencia". Se hace una revisión de los momentos más significativos del conflicto y, como principal hallazgo, se ofrece el trabajo etnográfico sobre la experiencia de lucha de la comunidad, buscando documentar la vitalidad de los sujetos subalternos, cuya existencia jurídicaera negada mediante acciones jurídicas por parte del Estado mexicano, pero que finalmente lograron ser reconocidos.

Palabras clave: antropología jurídica, indígenas, diferencia, derechos, conflicto

\begin{abstract}
This is a work of legal anthropology on the conflict between the Mexican State and the community of San Francisco Xochicuautla, Lerma, State of Mexico. It is suggested that this conflict is part of a chain of legal processes that have not definitively resolved the presence of indigenous peoples within the Mexican state. The central approach is that the Mexican legal system and the political practices of its rulers are part of a legal-political context in which episodes are presented that make visible some "contentious forms of difference". A review is made of the most significant moments of the conflict and, as the main finding, ethnographic work is offered on the community's experience of struggle, seeking to document the vitality of the subaltern subjects, whose legal existence was denied by legal actions on the part of of the Mexican State, but that they finally managed to be recognized
\end{abstract}

Key words:legal anthropology, indigenous, difference, rights, conflict

\footnotetext{
- Licenciado en Antropología Social por la Universidad Autónoma del Estado de México, email:doppelganger3.1416@gmail.com

• Doctor en Ciencias Sociales por la Universidad Autónoma del Estado de México. Líder del Cuerpo Académico

"Patrones culturales de las relaciones sociales", e-mail:jlarriagao@gmail.com
}

Recibido: 31/1/2018 Aceptado con correcciones: 25/11/2019 
Leyva César, M. y Arriaga Ornelas, J.L. La defensa del territorio de San Franciso Xochicuauutla, México, como una forma contenciosa de la diferencia. Derecho y Ciencias Sociales. Noviembre 2019 - Abril 2020 N $^{\circ} 22$. Pgs 144 - 166. ISNN 1852-2971 Instituto de Cultura

Jurídica y Maestría en Sociología Jurídica. FCJ y S. UNLP

\section{La defensa del territorio en San Francisco Xochicuautla, México, como una forma contenciosa de la diferencia}

Mario Leyva César

José Luis Arriaga Ornelas

\section{Introducción}

El estudio del conflicto ha resultado de interés para la Antropología desde sus inicios (Krotz, 2002). Puede sostenerse que habrá materia antropológica donde quiera que exista un sistema social regulando el comportamiento humano (Kelsen, 2009); y dicho interés reside en que las normas constituyentes de cualquier orden social lo que hacen es definir (para regular) los conflictos relevantes dentro de tal sistema, por lo cual terminan evidenciando lo que para ese grupo humano es, existe, se necesita, es fundamental o constituyente (y, por oposición, también implica lo que no es, lo que no existe, lo que es prescindible o impertinente). Un conflicto central en los países latinoamericanos es el tipo de relación que impusieran los Estados nacionales a los pueblos originarios (Stavenhagen, 1988); y, dada la emergencia en el escenario político latinoamericano de finales del siglo XX de organizaciones indígenas reivindicando derechos propios (Sierra, 1996), se ha vuelto evidente el interés en el desarrollo de estudios críticos sobre la legalidad (Sierra y Chenaut, 2002), mismos que cuestionan lo que Fritzpatrick (1992) llama el mito del derecho moderno.

Igualmente han sido materia de estudio antropológico los procesos de lucha que han derivado en distintos grados de reconocimiento de la diversidad cultural y los derechos de los pueblos indígenas, a lo que Yrigoyen (2012) denomina como el "horizonte pluralista"que se presentó sobre todo en el inicio del siglo XXI en buena parte de los países latinoamericanos. Sin embargo, la presencia de luchas por justicia indígena, que se encuentran presentes hoy, en oposición o al margen del Estado, cuestionando incluso laspolíticas de reconocimiento de derechos o la falta de acceso a la justicia, la violación a los derechos humanos y la violencia (Sierra, 2007), son evidencia de que existen conflictos jurídico-culturales que es preciso entender.

El tipo de conflicto del que se ocupa la Antropología Jurídica es el "conflicto regulado" (Radcliffe-Brow, 2010): aquel que está relacionado con un sistema de reglas básicamente aceptadas por la sociedad en cuestión. Pero, si bien tal noción alude a aquella situación en la que 
Leyva César, M. y Arriaga Ornelas, J.L. La defensa del territorio de San Franciso Xochicuauutla, México, como una forma contenciosa de la diferencia. Derecho y Ciencias Sociales. Noviembre 2019 - Abril 2020 N $^{\circ} 22$. Pgs 144 - 166. ISNN 1852-2971 Instituto de Cultura Jurídica y Maestría en Sociología Jurídica. FCJ y S. UNLP

una sociedad está puesta en la condición de establecer reglas para su convivencia, ello no debe interpretarse como observación escrupulosa y unánime de las mismas, sino como "recurso en una disputa" (Krotz, 2002: 21). Por esta razón es pertinente plantear el estudio de disputas o luchas concretas para, a través de ellas, atisbar la normatividad operante en esa sociedad, su historia, vacíos, indeterminaciones, incosistencias e incluso contrasentidos.

El presente artículo se ocupa de un conflicto específico: el derivado de un proyecto carretero que busca comunicar a la capital del Estado de México (Toluca) con la Zona Metropolitana de la Ciudad de México (ZMCM), pero que hasta ahora se encuentra inconcluso por la resistencia de algunas comunidadesque se dicen afectadas por su trazo (especialmente la de San Francisco Xochicuautla, perteneciente al municipio de Lerma, Estado de México; aunque también se ha visto oposición a este proyecto en Huitzizilapan, Lerma, y Ayotuxco, Huixquilucan, también en el Estado de México); pero ofrece hacerlo hurgando desde el fenómeno jurídico que ahí se asoma y que puede capturarse en el concepto "formas contenciosas de la diferencia" que proponen Brighenti y Gago (2017). Este término debe entenderse -dicen Brighenti y Gago- como "los modos en que la diferencia es productora de conflicto, de tensión, y que no se pueden asimilar a una variedad pacificada" (2017: 54). Al hablar de conflicto este trabajo no lo constriñe a la disputa, sino que emplea la noción como una herramienta teórica para aproximarse y estudiar el orden social y los mecanismos de ruptura, negociación, mediación y equilibrio sociales (Berruecos, 2009). En el trabajo se hace un recuento del proceso de lucha de la comunidad de San Francisco Xochicuautla, a lo largo del litigio por el proyecto carretero y su defensa del territorio, hasta conseguir su reconocimiento como comunidad poseedora de derechos colectivos.

\section{El conflicto histórico entre el Estado y los pueblos indígenas en México}

El proceso de conquista del territorio americano a manos de la Corona española en el siglo XVI debe entenderse como un conflicto distinto al "regulado": mas bien fue un tipo de conflicto caracterizado por una ausencia general de normas o convenios: "es la situación de violencia sin límites, de la guerra" (Krotz, 2002: 21), el cual suele presentarse en la confrontación entre sociedades distintas. Concluida esta etapa, la instauración de instituciones de explotación en territorio colonizado generó otro escenario: la necesidad de regular la convivencia entre españoles e indígenas (y posteriormente criollos, mestizos, castas, etc.). Para tales efectos, se creó el Derecho Indiano, es decir todo un conjunto de normas jurídicas especialmente producidas 
Leyva César, M. y Arriaga Ornelas, J.L. La defensa del territorio de San Franciso Xochicuauutla, México, como una forma contenciosa de la diferencia. Derecho y Ciencias Sociales. Noviembre 2019 - Abril 2020 N $^{\circ} 22$. Pgs 144 - 166. ISNN 1852-2971 Instituto de Cultura Jurídica y Maestría en Sociología Jurídica. FCJ y S. UNLP

por la Corona española para dar vida a "un sistema político, religioso y económico que correspondiera a su concepción absolutista del poder, lo que requería una abundante legislación" (Dougnac, 1994:12). Ahora, si se asume como históricamente cierto que desde la instauración de la Colonia hasta la actualidad el reclamo indígena ha sido ininterrumpido (Kubli-García, 2006), emerge de inmediato la materia del principal conflicto a regular desde la conformación de la sociedad colonial: la diferencia entre indígenas y no indígenas, quienes deben convivir permanentemente.

En México, como en otras partes de América Latina, esta materia de conflicto tendría un hilo de continuidad histórica que hilvana la sociedad colonial con la posterior al movimiento de Independencia y con la emergida de la Revolución y correspondiente a la Constitución de 1917, vigente hasta la fecha. A lo largo de todos estos siglos ha estado presente ese conflicto que consiste "básicamente en la relación entre los pueblos indígenas y los Estados (Stavenhagen, 2010: 13). Regular esta relación -y por añadidura la convivencia entre indígenas y no indígenasfue materia del Derecho Indiano, que luego se articuló con la "ley criolla", las ordenanzas y bandos de los virreyes y gobernadores, el derecho canónico indiano y, claro, la costumbre: "contra lo que ha dicho con insistencia la leyenda negra antiespañola, la Corona no acabó con las costumbres indígenas salvo en la medida en que éstas contrariaran la religión católica o atentaran contra los derechos políticos del rey" (Dougnac, 1994: 13-14).

Puede apreciarse que, durante la etapa colonial, el asunto de la diferencia se resolvió a través del Derecho Indiano: se reconocía la existencia de los pueblos indios y se regulaba su actuar. Este cuerpo de normas se convertía(potencialmente) en "recurso en una disputa", que no eran pocas, por cierto, sea en materia de posesión de la tierra, de disposición de agua, de tributos, de coacción de diversa índole, por mencionar sólo algunas. El conflicto entre los habitantes de la Nueva España estaba regulado bajo dos principios: heterogeneidad y jerarquía (Navarrete, 2010), lo cual no quiere decir -insistimos- observación escrupulosa y unánime de las normas por parte de todos los sujetos, ni tersa coexistencia.

Es un hecho que las disputas, diferencias, desacuerdos o controversias tenían cauce para ser resueltas y esta solución jurídica, que reconoce la existencia del indígena, después se traduce en cómo se le piensa. En primer lugar, la noción de indio es utilizada como herramienta muy útil para homogeneizar a las sociedades muy diferentes que habitaban América y subordinarlas 
Leyva César, M. y Arriaga Ornelas, J.L. La defensa del territorio de San Franciso Xochicuauutla, México, como una forma contenciosa de la diferencia. Derecho y Ciencias Sociales. Noviembre 2019 - Abril 2020 N $^{\circ} 22$. Pgs 144 - 166. ISNN 1852-2971 Instituto de Cultura

Jurídica y Maestría en Sociología Jurídica. FCJ y S. UNLP

jurídica y políticamente (Bonfil, 1995). En segundo término, el "Derecho Indiano es esencialmente evangelizador" (Dougnac, 1994: 18). Siendo los reyes castellanos católicos, piensan al indio desde su visión espiritual del mundo y les parece un ser pagano, necesitado de salvación, al que hay que evangelizar, redimir, proteger, tutelar. Los medios para operativizar esta visión serían instituciones como el Real Consejo de Indias, la Casa de Contratación de las Indias, la Real Audiencia, los Repartimentos y la Encomienda (Uriarte, 2013).

Nunca debe perderse de vista la condición colonial en la que se da el reconocimiento del indígena y en la que se le alteriza: siempre se tratará de una imposición a los otros de una especie de ley de lo mismo: "la mismidad que persigue por doquier a la alteridad, (operando como) un aparato de poder que se articula y sostiene a partir de un doble mecanismo diferenciador: por un lado, la ilusión de reconocer las diferencias del otro (...); por otro lado, y al mismo tiempo, el de repudiar esas mismas diferencias, disimularlas, enmascararlas, desactivarlas hasta convertirlas en puro exotismo, en pura alteridad" (Skliar, 2002: 91-92). Y este aparato colonial será, esencialmente, un aparato de producción de conocimientos: de un saber y una verdad que son indispensables para la alterización del otro (aunque luego ese saber se transfiere al interior del colonizado hasta llegar a parecerle verdad natural), todo lo cual entra en una paradoja cuando los alterizados se comportan como formas contenciosas de la diferencia. Ya se abordará esto más adelante.

Más tarde, en el siglo XIX, en el marco de las luchas de indepencencia y la conformación de las modernas naciones latinoamericanas, el "Derecho nuevo que nació, entrañablemente unido, sin embargo, al que lo precedió" (Gross, 2002: 144),gestionará el conflicto implicado en la convivencia entre indígenas y no indígenas con los principios de la matriz de pensamiento racional, liberal, modernizadora (Argumedo, 2009) que implicó "un proyecto mestizo,excluyente delo indígena y dela diversidad" (Velasco, 2013: 69). Baste recordar, por ejemplo, el Bando emitido por José María Morelos el 17 de noviembre de 1810 para abolir las castas, proclamando que en lo sucesivo "no se nombrarán indios, mulatos ni castas, sino todos naturalmente americanos". Por eso hay quien afirma que "el liberalismo mexicano destruyó más comunidades en un siglo de las que la Colonia destruyó a lo largo de trescientos años" (Montemayor, 2001: $65)$. 
Leyva César, M. y Arriaga Ornelas, J.L. La defensa del territorio de San Franciso Xochicuauutla, México, como una forma contenciosa de la diferencia. Derecho y Ciencias Sociales. Noviembre 2019 - Abril 2020 N²2. Pgs 144 - 166. ISNN 1852-2971 Instituto de Cultura Jurídica y Maestría en Sociología Jurídica. FCJ y S. UNLP

En otros términos, el modo de regular la convivencia de los individuos en los emergentes estados nacionales sería eliminando completamente las distinciones jurídicas entre los diferentes grupos étnicos (Navarrete, 2010). Pero, igualmente, los principios de igualdad y universalidad que articularían el nuevo andamiaje jurídico no serían observados "de inmediato ni de manera escrupulosa" por todos, dado que venían a sobreponerse sobre los órdenes sociales, la costumbre y mentalidad de una sociedad colonial que, como ya se dijo, había sido constituida sobre la heterogeneidad y la jerarquización étnicas, solidificadas a lo largo de siglos. Como afirma Gros, tanto "el Derecho del periodo español, como el Derecho escrito de la Revolución y de la Independencia era, para estas sociedades indígenas, Derecho formalmente vigente, pero no Derecho vivo ni real" (2002: 144)

Debe resaltarse que en el nuevo marco regulatorio del conflicto posterior a la Independencia el indio ya no existe: en términos jurídicos es asimilado a la categoría universal de ciudadano. "La condición de ciudadanos les fue concedida en las Cortes de Cádiz, del mismo modo que la Constitución de Apatzingán en 1814 y la primera república en 1824, al proclamar la igualdad de todos los habitantes abrieron paso a la ciudadanización de los indígenas" (Ibarra, 2012: 213). Igualmente, "los reformadores de la década que arrancó en 1830 hicieron caso omiso del indio y cifraron las esperanzas de futuro en la nueva clase de propietarios burgueses, fortificada por europeos inmigrantes" (Hale, 1972).

En consecuencia, si se niega jurídicamente la existencia de los pueblos indígenas, no sólo se anula el recurso a su condición cultural y étnica en una disputa, sino que se cancela la posibilidad de pensarlos como pueblos con características, dinámicas, valores, prácticas, costumbres y saberes distintos, que existen y viven.

Los constituyentes imaginaron la fundación de una nación con una sola lengua, una sola religión y una sola cultura, superpuesta en el imaginario del progreso y la civilización. Bajo estas condiciones se imponía la creación del ciudadano, pero para ello era precisa su invención; la misma tuvo que nacer de la oposición a lo que desde entonces se convirtió en la alteridad, los indígenas. Dejar de ser indio implicaba convertirse en ciudadano y pasar a formar parte de una nación (...) se inventa al ciudadano por oposición a lo que ya no será más. Uno de los caminos para eludir el problema de la indianidad de México ha sido convertir ideológicamente a un sector de la población nacional en el depositario único de los remanentes que, a pesar de todo, se admite que persisten de aquel pasado ajeno (...) aquí había ahora una otredad fundacional, fuente de nacionalismo, interesantísima para ser estudiada, pero -insiste Bonfil Batalla- muerta (Ramírez y Arriaga, 2011: 93-94) 
Leyva César, M. y Arriaga Ornelas, J.L. La defensa del territorio de San Franciso Xochicuauutla, México, como una forma contenciosa de la diferencia. Derecho y Ciencias Sociales. Noviembre 2019 - Abril 2020 N $^{\circ} 22$. Pgs 144 - 166. ISNN 1852-2971 Instituto de Cultura Jurídica y Maestría en Sociología Jurídica. FCJ y S. UNLP

La Revolución Mexicana y el orden constitucional que de ella emana no se apartaron de estas condicionantes jurídicas, políticas y epistémicas. Ciertamente a la Constitución de 1917 se le reconoce como modelo paradigmático del constitucionalismo social (Wolkmer y Mánica, 2016), quepermitió lapositivación de derechos sociales y estableció un paradigma de Estado social, pero sigue reflejando la colonialidad (Mignolo, 2005) en sus diversas formas. Y debe subrayarse que se suscitó una importante corriente nacionalista en México, que se reflejó en los diversos planes políticos, en la Constitución política de 1917 y posteriormente en la ideología oficial que fue bautizada con el concepto de "Nacionalismo revolucionario". Una de sus facetas más visibles fue el nacionalismo cultural que prosperó en las décadas de los veinte y treinta del siglo XX: al mismo tiempo que abogaba por el desarrollo de la cultura nacional, la soberanía de México sobre sus recursos y su derecho a determinar su propio destino, encomendaba esta patriótica tarea a la raza mestiza. "Los indígenas, quienes a principios del siglo $\mathrm{XX}$ constituían, según datos censales, un $15 \%$ de la población nacional, debían ser integrados y desaparecer como tales" (Stavenhagen2013:25).

Vale la pena destacar que la participación de las comunidades indígenas en el movimiento revolucionario obedecía, sobre todo, a los problemas económicos que enfrentaban, especialmente el de la tenencia de la tierra, consecuencia directa del proceso de privatización llevado a cabo durante el siglo XIX. Los pueblos y comunidades indígenas seguían estando ahí, seguían haciéndose presentes pero, dado que jurídicamente "no existían", ningún derecho histórico, cultural y territorial, podría ser legalmente reclamado por el grupo. "El indio se convierte en sujeto jurídico como un ciudadano más, pretendiendo así borrar de una vez su separación, pero también anular su perfil diferenciador (González, 1997: 2).

En esta nueva solución al tema de la diferencia, epistemológicamente sí era posible delimitar al indígena, de hecho la Revolución Mexicana coincide temporalmente con el establecimiento formal de la antropología en México, con la presencia de la escuela de Franz Boas y la celebración del Congreso de Americanistas en México en 1910. Entonces, como objeto de estudio, la población indígena propiciará una abundante proliferación de discursos y de diseños de políticas indigenistas, pero no serían incluidos en la conformación del nuevo Estado nacional. O sea, no hay un reconocimiento de su personalidad jurídica como parte de colectividades orgánicas; no hay un reconocimiento de su autonomía política, social, territorial, económica (Ramírez y Arriaga, 2011). 
Leyva César, M. y Arriaga Ornelas, J.L. La defensa del territorio de San Franciso Xochicuauutla, México, como una forma contenciosa de la diferencia. Derecho y Ciencias Sociales. Noviembre 2019 - Abril $2020 \mathrm{~N}^{\circ} 22$. Pgs 144 - 166. ISNN 1852-2971 Instituto de Cultura Jurídica y Maestría en Sociología Jurídica. FCJ y S. UNLP

No será sino hasta finales del siglo XX que comienza a discutirse la pertinencia de esta solución dada a la diferencia y a sus derivaciones en conflictos. Desde los años 70 se criticó la política indigenista, se empieza a reconocer la pluralidad étnica del país, se reivindican las lenguas indígenas y la instrumentación de programas de educación bilingüe bicultural. Y con el levantamiento en armas del Ejercito Zapatista de Liberación Nacional (EZLN) en 1994 vendrá un impulso definitivo para la modificación del marco jurídico: una nueva regulación del conflicto derivado de la diferencia. Estos pueblos y comunidades indígenas organizados y movilizados serían los que forzarían un diálogo con el Estado para negociar los términos de las reformas constitucionales que modificarán el estatus jurídico que históricamente se les había negado y que indebidamente había sido olvidado por "nuestros constitucionalistas hasta aproximadamente los años noventa, cuando en el artículo 4o. constitucional se pone la semilla de lo que ocurriría después en términos jurídicos" (López y Rivas, 2002:113).

Lograr que se incluyera a los indígenas en la Constitución implicaba reconocer jurídicamente su existencia, su continuidad histórica en términos culturales y su capacidad de autodeterminación. Devolverles tal estatus jurídico implicaba posibilitar que ellos jurídicamente tuvieran ese recurso en una disputa. Se trataba de una nueva regulación de la diferencia que, al incluirse en el marco normativo, generaba nuevas condiciones de relación con los no indígenas. ${ }^{1}$

El resultado de todo este proceso en México sería la reforma constitucional de los artículos 1, 2, 4, 18 y 115, que generan las condiciones en las que ahora se pueden analizar los conflictos y las expresiones de "formas contenciosas de la diferencia" que representan los pueblos indígenas del país, a los cuales se les ha visto convertirse en años recientes "en sujetos políticos con una utopía común bien definida: ser reconocidos dentro de las sociedades en las que viven con plenos derechos" (López Bárcenas, 2016: 60) En el siguiente apartado se abordará específicamente el

\footnotetext{
${ }^{1}$ Existe toda una discusión teórica más o menos reciente al respecto de los procesos a través de los cuales los Estados modernos producen su alteridad y la controlan para contener la organización social y allanar el camino a un modelo de economía capitalista. La argumentación principal es en el sentido de que dichos procesos despojan de su humanidad a quienes se defienden de este modelo civilizatorio, al desplazarlos de las zonas de influencia y reconocimiento de los derechos humanos (zona del ser), hacia a la zona del no-ser, en donde la violencia, la injusticia y los abusos son parte de ese despojo de la humanidad, para el exterminio y su posterior incorporación al mercado mundial. "Los modos como se regulan los conflictos en cada zona son también distintos, en la primera (zona del ser)existen espacios de negociación, se reconocen los derechos civiles, laborales y humanos de las personas, funcionan los discursos sobre la libertad, la autonomía y la igualdad, y los conflictos se gestionan mediante métodos no violentos, o por lo menos la violencia es la excepción. En la zona del no-ser, a la que también define como la línea debajo de lo humano, los conflictos son regulados mediante la violencia y sólo de forma excepcional se usan métodos no violentos" (Grosfoguel, en Zibechi, 2014: 82-83).
} 
Leyva César, M. y Arriaga Ornelas, J.L. La defensa del territorio de San Franciso Xochicuauutla, México, como una forma contenciosa de la diferencia. Derecho y Ciencias Sociales. Noviembre 2019 - Abril 2020 N $^{\circ} 22$. Pgs 144 - 166. ISNN 1852-2971 Instituto de Cultura

Jurídica y Maestría en Sociología Jurídica. FCJ y S. UNLP

caso del conflicto de la comunidad de San Francisco Xochicuautla con el Gobierno del Estado de México y la empresa Autovan, detonado por la construcción de una carretera que uniría a la Ciudad de México con la ciudad de Toluca, cruzando el territorio de varias comunidades, algunas de ellas indígenas. Primero se hará un recuento de los hechos y acciones de los involucrados en el conflicto para, posteriormente, llevar a cabo una reflexión sobre cómo la comunidad pasa a través devarias instancias contenciosas del conflicto hasta conseguir el reconocimiento de su personalidad jurídica y de su diferencia como indígena.

\section{San Francisco Xochicuautla y la defensa del territorio otomí}

La comunidad indígena ñatho de San Francisco Xochicuautla es una de las delegaciones del municipio de Lerma de Villada, en el Estado de México, aproximadamente a 40 kilómetros de la capital del país. De acuerdo al Censo de Población y Vivienda del año 2010, en la comunidad habitaban 3,613 personas: 1,770 hombres y 1,843 mujeres (INEGI, 2010). La localidad se encuentra en una zona del denominado "Bosque de Agua", el cual abarca diferentes municipios del Estado de México:Ocoyoacac, Nicolás Romero, Temoaya, Otzolotepec, Huixquilucan y Xonacatlán; este bosque sagrado otomí-mexica es una de las partes mejor conservadas de la región en términos ecológicos, a pesar de evidentes procesos de urbanización y fraccionamiento de algunas zonas, como el Proyecto Santa $\mathrm{Fe}^{2} \mathrm{y}$ otros desarrollos que se inscriben en las dinámicas de expansión de la ZMCM, "lo que ha creado una urbanización dispersa que forma parte de la zona suburbana de la ZMCM, separada sólo por la barrera montañosa donde los bosques son protegidos, interrumpiendo la urbanización únicamente por unos $20 \mathrm{~km}$ de longitud" (Bataillon, 2008:37).

Se trata de un territorio de gran importancia histórica por la riqueza arqueológica que se encuentra en los cerros adyacentes a las comunidades, las cuales descienden de los habitantes indígenas del valle matlazinca (hoy llamado valle de Toluca y que incluye a la zona conurbada de ésta ciudad, entre las cuales están los municipios de Metepec, Lerma, San Mateo Atenco y, Ocoyoacac, Almoloya del Río y Otzolotepec), mismo que fungió durante mucho tiempo como

\footnotetext{
${ }^{2}$ Se trata de un proyecto inmobiliario que atraviesa una zona sagrada para el pueblo ñatho, por ser donde realizan peregrinaciones y rezos de forma periódica. En este lugar la empresa inmobiliaria logró apropiarse del lugar sagrado llamado Nacelagua, en donde fue erigida una capillita para encerrar una piedra sagrada, todo lo cual fue parte del acuerdo del fideicomiso entre Reserva Santa Fe y ciertos ejidatarios de Atarasquillo, quienes vendieron esas tierras y ahora Nacelagua, se encuentra en propiedad privada. Pueden revisar la documentación de este caso en el video https://www.youtube.com/watch?v=oCl1RO7O_KQ.
} 
gran proveedor de maíz y otros insumos acuáticos, pues la zona lacustre de Chignahuapan era un sitio donde los pueblos nahuas, matlazincas, otomíes y mazahuas, habían sido aliados o enemigos, en la gran conquista emprendida por Ayaxacatl en 1476. Se libraron varias batallas en diferentes partes del valle, entre las que destacan las de Tlacotepec, Teotenango, Temoaya, de donde era originario el célebre jefe Botzanga (Lagartija negra), quien hirió al tlatoani mexica en un muslo durante la batalla de Calixtlahuaca (Pérez, 2007).

Durante la conquista española, el valle matlazinca fue sometido por el oficial de Cortés Gonzalo de Sandoval y sus aliados indígenas, durante el último año del sitio a Tenochtitlán en 1521. En la época de la Colonia la región, tanto del valle de Toluca como de las montañas del alto Lerma, fueron parte activa de la economía del virreinato de la Nueva España. En el año de 1613 se funda la villa de Lerma por Martín ReolínBarejón. Cabe señalar que durante el trabajo de campo en la comunidad se logró saber de la existencia de una Merced Real en donde se declara, por parte de la Corona española y de las autoridades coloniales, el reconocimiento de una República de Indios, ${ }^{3}$ en las inmediaciones del bosque otomí-mexica. Este documento estaría en posesión de el Sr. Juan Villegas, de la comunidad de Ayotuxco, municipio de Huicquilucan, Estado de México.

Ya en época de la Independencia, la región fue escenario de la Batalla del Monte de las Cruces, encabezada por Miguel Hidalgo. Igualmente, durante la época de la Revolución en esta zona se dio la destrucción de la hacienda de San Nicolás Peralta por parte de las tropas zapatistas. En el caso de Xochicuautla, hubo habitantes que participaron en diferentes hechos de armas, como cuenta Don Antonio Reyes, una de las autoridades tradicionales de la comunidad, quien incluso conserva una carabina 30-30, regalo de su abuelo:

"Acá nos contaba mi abuelito que había habido una emboscada, que había habido balazos en la parte baja del cerro, acá cerca de la Concha, y que desde los barrancos se tiraban, y que hubo unos muertos, y siempre nos decía que era por pelear las tierras que nos había

\footnotetext{
${ }^{3}$ Territorio producto de la división social y política que formó parte de la administración colonial, en ella se reconocia el derecho de los pueblos para con sus tierras, siempre y cuando se evangelizaran y tributaran sus recursos naturales, era por así decirlo , el precio de la supervivencia ante el colonizador europeo y parte de las estrategias de adaptación y resistencia que implementaron los pueblos indígenas para la defensa de sus territorios y que el nacimiento de la nación mexicana; la imaginada por criollos y mestizos, éstos terminaron con la autonomía que gozaban estas repúblicas de indios, pues con las leyes de reforma se nacionalizaron los bienes que la iglesia católica administraba (entre los cuales los pueblos indígenas habían mantenido la defensa de sus territorios, mediante la donación de estos a la iglesia) y que con dichas leyes se pudieron vender para ser latifundios individuales.
} 
Leyva César, M. y Arriaga Ornelas, J.L. La defensa del territorio de San Franciso Xochicuauutla, México, como una forma contenciosa de la diferencia. Derecho y Ciencias Sociales. Noviembre 2019 - Abril 2020 N $^{\circ} 22$. Pgs 144 - 166. ISNN 1852-2971 Instituto de Cultura Jurídica y Maestría en Sociología Jurídica. FCJ y S. UNLP

pertenecido desde antes de la revolución" (Don Antonio Reyes, trabajo de campo, del día 27 de marzo del 2014.

La población de San Francisco Xochicuautla se denomina a sí misma indígena otomí o ñatho, aunque la demarcación se encuentra habitada por familias de varias generaciones de campesinos y migrantes al Distrito Federal. Este posicionamiento cultural tiene dentro del contexto político una relevancia primordial, por ser precisamente este auto-reconocimiento, llevado a cabo desde muchos años atrás, una de las causas identitarias, sumada a que existen personas que aún hablan el ñatho de esta región y a la existencia de diferentes danzas (arrieros) y tradiciones (como las subidas a los cerros y encendidos del fuego nuevo). Testimonios recabados en campo hablan de la identidad de sus habitantes.

Xochicuautla era un pueblo unido, antes de que llegara el proyecto carretero las familias y los amigos convivían, antes no había esta clase de divisiones, lo que pasa es que corrompen a la gente y nos echan a pelear." (Jaime Vargas, comunero de Xochicuautla, en la conferencia sobre el problema en San Francisco, durante el II Congreso de la Red de Antropologías Populares del Sur, en la UAQ, septiembre 19 de 2013.)

Los territorios sagrados e hídricamente importantes para la región se entrelazan con el sentido comunitario de sus habitantes, mismo que se ha reivindicado de manera reciente, justo a raíz del proyecto carretero. En palabras de Nicolás Ramírez:

"Van a destruir el pueblo, pues incluso en páginas de bienes raíces y de conjuntos residenciales, como Reserva Santa Fe, se puede comprar terrenos de las comunidades que ya vendieron, lo cual en Xochicuautla generaría una división social mayor de la que ya se tiene, pues no solo sería la carretera, sino también sería las empresas y las casas para ricos."(Durante la compartición "Solidaridad en la lucha de la defensa por los territorios.", donde se contó con la presencia de representantes de la tribu yaqui, el día 16 de mayo del 2014, en la Facultad de Antropología de la UAEMex.).

Es en esta región, ubicada justo en los bosques que interrumpen la urbanización entre la ZMCM y la Ciudad de Toluca, donde se presenta el conflicto al que se dirige ahora la atención del presente trabajo. Se trata de una disputa entre las comunidades asentadas en la zona y el Estado (por estar involucrados en distintas maneras los gobiernos municipal, estatal y federal), por la construcción de una carretera privada. El conflicto propiamente dicho tiene sus antecedentes en el año 2005, cuando -a decir de algunos lugareños entrevistados mediante trabajo de campo- se crea el primer padrón de comuneros, posibilitando que los afiliados en él pudieran determinar el cambio de uso de suelo en la comunidad y así permitir la construcción, concesionada a 
Leyva César, M. y Arriaga Ornelas, J.L. La defensa del territorio de San Franciso Xochicuauutla, México, como una forma contenciosa de la diferencia. Derecho y Ciencias Sociales. Noviembre 2019 - Abril 2020 N $^{\circ} 22$. Pgs 144 - 166. ISNN 1852-2971 Instituto de Cultura

Jurídica y Maestría en Sociología Jurídica. FCJ y S. UNLP

particulares. Algunos de estos informantes consideran esta primera acción como parte de una estrategia política del Estado, destinada a fragmentar la comunidad en la toma de decisiones sobre la tenencia de la tierra, ya que antes de la creación de este padrón de comuneros (aproximadamente 882 fueron incluidos en él), la asamblea comunitaria era la que decidía sobre las tierras comunales.

En el año $2007^{4}$ el gobierno estatal anuncia, a través de su Gaceta de Gobierno, el resultado de una licitación para la construcción de la carretera Toluca-Naucalpan (el proyecto fue otorgado a Grupo HIGA mediante la licitación pública No SCEM-CCA-01-06., y autorizado mediante el oficio No DFMARNAT/1681/2010), que cruzaría por las montañas del Alto Lerma, hogar de los milenarios pueblos ñathos. La obra se realizaría por la constructora Autovan, parte del consorcio empresarial Grupo HIGA. ${ }^{5}$ Días después de esto los habitantes de Xochicuautla sorprenderían al personal de dicha empresa talando árboles para la proyección del trazo carretero. Después de expulsarlos y reforestar el lugar, se desencadenaron una serie de sucesos que se consignan en la Tabla 1, elaborada a partir de una aproximación etnográfica en la comunidad.

\footnotetext{
${ }^{4}$ De acuerdo con los datos presentados durante un seminario jurídico realizado en la comunidad los días 15 y 16 de febrero del 2013 y en el cual se realizó una línea de tiempo, el inicio del conflicto con la empresa y el gobierno se dio el día 24de abril del 2007, mediante la licitación de la obra. A su vez el 7 de septiembre se otorga la concesión y el día 24 de octubre se pronuncian los comuneros.

${ }^{5}$ Entre los habitantes de la comunidad y otros actores políticos y sociales que se han convertido en sus interlocutores, existe la convicción de que este proyecto carretero forma parte de compromisos políticos asumidos por quien fue gobernador del Estado de México y luego presidente de la República, Enrique Peña Nieto, con el propietario del Grupo HIGA, a quien trabajos periodísticos lo ubican como uno de los principales proveedores del gobierno y amigo personal de Peña, razón por la cual se ha visto "favorecido" en varias licitaciones. Como muestra de esto pueden consultarse los archivos de la revista Proceso: http://www.proceso.com.mx/tag/grupo-higa.
} 


\section{Tabla 1}

\begin{tabular}{|c|c|}
\hline Año & Suceso. \\
\hline 2007 & $\begin{array}{l}\text { En los primeros días del mes de diciembre de } 2007 \text { habitantes de la comunidad sorprenden y expulsan } \\
\text { del lugar a un grupo de trabajadores de la empresa encargada de la obra, quienes -a decir de los } \\
\text { pobladores- se encontraban realizando mediciones y algunos otros trabajos técnicos, como parte del } \\
\text { inicio de la construcción de la carretera Toluca- Naucalpan. La gente de la comunidad señaló a los } \\
\text { trabajadores que no habían sido notificados de la realización de obra alguna. De acuerdo con gente de } \\
\text { la comunidad, tras estos sucesos hubo incipientes intentos de dialogar con el Gobierno del Estado, pero } \\
\text { ello no fructificó dada la negativa de los funcionarios a tratar con representantes en calidad de } \\
\text { miembros de una comunidad indígena. En adelante la comunidad se re-organizó al interior y, mediante } \\
\text { asambleas decidió movilizarse en distintos frentes apara manifestar su rechazo al proyecto. }\end{array}$ \\
\hline 2011 & $\begin{array}{l}\text { El } 15 \text { de mayo de } 2011 \text {, en el marco de la "Primera Cumbre de los Pueblos Originarios de la Zona } \\
\text { Protegida Otomí-Mexica", convocada para "exigir un alto a la destrucción y las amenazas en contra de } \\
\text { la naturaleza y su cultura" se constituye el Frente de Pueblos Indígenas en Defensa de la Madre Tierra, } \\
\text { mediante un documento hecho público en el que se declara que el Frente de Pueblos Indígenas en } \\
\text { Defensa de la Madre Tierra es un conjunto de comunidades, científicos, académicos, campesinos, } \\
\text { organizaciones y ciudadanos en general, interesados en defender el medio natural que aún existe en } \\
\text { nuestra región, así como los derechos de los pueblos indígenas que han pertenecido y cuidado este } \\
\text { territorio ancestralmente. } \\
\text { El } 14 \text { de agosto de } 2011 \text { el Comisariado de Bienes Comunales de San Francisco Xochicuautla celebró } \\
\text { una asamblea general (resguardada por la fuerza pública estatal, ante la efervescencia política debido a } \\
\text { las acusaciones intracomunitarias sobre la legalidad de dicha asamblea y del patrón de comuneros bajo } \\
\text { el cual se convocaba) en la que se acordó por los asistentes aprobar el proyecto carretero. }\end{array}$ \\
\hline 2012 & $\begin{array}{l}\text { El } 30 \text { de abril de } 2012 \text {, se convocó a una nueva asamblea por parte del Comisariado de Bienes } \\
\text { Comunales con la intención de dar cauce al acuerdo de aprobar el proyecto e iniciar con la entrega de } \\
\text { una indemnización acordada a cada uno de los que había firmado el acuerdo (un total de } 40 \text { mil pesos } \\
\text { mexicanos para cada uno). Esta asamblea implicó el mayor operativo policiaco hasta ese momento en } \\
\text { el lugar, en el que se desplegó a cientos de elementos de varias corporaciones y agrupamientos, a nivel } \\
\text { municipal y estatal, para controlar el acceso a la asamblea e incluso al pueblo. }\end{array}$ \\
\hline 2013 & $\begin{array}{l}\text { El } 13 \text { de mayo de } 2013 \text { se convocó a una nueva asamblea general por parte del Comisariado de Bienes } \\
\text { Comunales y desde la mañana de ese día la comunidad volvió a verse en medio de un operativo } \\
\text { policial que, en esta ocasión, derivó en algunos enfrentamientos y la detención de } 14 \text { personas que } \\
\text { buscaban manifestarse e ingresar al inmueble donde se celebraba la asamblea para denunciar la } \\
\text { ilegalidad de la misma. } \\
\text { El } 21 \text { de agosto de } 2013 \text { el Consejo Supremo Indígena y el Frente de Pueblos Indígenas en Defensa de } \\
\text { la Madre Tierra, entre otros actores, solicitaron a la Comisión Interamericana de Derechos Humanos su } \\
\text { intervención por considerar que estaban en riesgo varios de sus derechos inalienables como comunidad } \\
\text { indígena. La queja fue admitida y la Comisión se pronunciaría años más tarde }{ }^{6} \text {. }\end{array}$ \\
\hline
\end{tabular}

${ }^{6}$ En el mes de Octubre se eligió el Consejo Supremo Otomí de San Francisco Xochicuautla. Cabe señalar que dentro de esta actividad, la ceremonia de investidura, las denuncias y las solidaridades estaban a la orden del día, pues hubo representantes de comunidades de otros estados de la República y activistas de diversos tipos En el evento se dijo: "la formación de este consejo supremo forma parte de nuestras estrategias de lucha, el volver a nuestras raíces, a nuestra organización es un desafío a sus políticas ecocidas, vamos a defender nuestro pueblo de una manera inteligente y pacífica y nuestros usos y costumbres deben ser respetados." (Nicolás Ramírez, testimonio recabado el día del evento). Los integrantes de este Consejo, cuatro hombres y cuatro mujeres, sellaron un pacto con su comunidad, con sus ancestros, con su territorio, para la defensa no sólo de sus bosques o recursos, sino como un grito de rebeldía: "La memoria se presenta como un principio de esperanza que guarda en su núcleo el sentido y la idea de un futuro que no es prolongación lineal y mecánica del presente, sino una escisión que implica la temporalidad del futuro en el presente de la lucha. Ese tiempo nuevo, en tanto potencia en marcha, surge cuando se 


\begin{tabular}{|c|c|}
\hline 2014 & $\begin{array}{l}\text { El } 7 \text { de octubre de } 2014 \text { trabajadores de la empresa Teya S.A. de C.V., responsables de la obra, } \\
\text { "acompañados y resguardados por policías de la Comisión Estatal de Seguridad Ciudadana del Estado } \\
\text { de México (Seguridad Ciudadana), talaron una gran cantidad de árboles sin exhibir el permiso } \\
\text { correspondiente" (CNDH, 2016: 3). Personas de la comunidad reclamaron el hecho, exigieron detener } \\
\text { la actividad por existir una sentencia definitiva del Juicio Agrario que se interpuso para declarar nula la } \\
\text { asamblea de bienes comunales en la que se aprobó el proyecto. Dos semanas después de tales hechos } \\
\text { los habitantes de la comunidad los denunciaron ante la Procuraduría General de la República, } \\
\text { señalando la probable comisión de los delitos de Desacato a una sentencia judicial y Daños } \\
\text { ambientales; igualmente denunciaron dos días más tarde ante la Procuraduría Federal de Protección al } \\
\text { Ambiente la tala ilegal de árboles así como la destrucción del suelo vegetal y manantiales de la } \\
\text { comunidad. }\end{array}$ \\
\hline 2015 & $\begin{array}{l}\text { El } 9 \text { de febrero de } 2015 \text { el Consejo Supremo Indígena de San Francisco Xochicuautla y otros actores } \\
\text { que han protagonizado la resistencia presentaron una queja ante la Comisión Nacional de Derechos } \\
\text { Humanos por la presunta violación a varios de sus derechos colectivos dentro del proceso para la } \\
\text { Construcción de la carretera. La queja fue admitida y casi dos años después derivó en una } \\
\text { Recomendación dirigida a autoridades federales y estatales. } \\
\text { El } 13 \text { de mayo de } 2015 \text { El Consejo Supremo Indígena de San Francisco Xochicuautla solicitó un } \\
\text { Amparo en contra de la planeación, licitación, adjudicación y construcción de la autopista por } \\
\text { considerar que violan sus derechos a la libre determinación, al territorio, a la integridad cultural, al } \\
\text { agua y a la consulta libre, previa e informada. El Amparo le fue concedido a la comunidad por distintas } \\
\text { fallas procedimentales en la consulta a la comunidad, ordenando el juez que se realizara una nueva, } \\
\text { atendiendo a los criterios de protección y tutela de los derechos que asisten a los pueblos indígenas. } \\
\text { El } 9 \text { de julio de } 2015 \text { el Presidente de la República emite un decreto expropiatorio sobre } 37.9 \text { hectáreas } \\
\text { "de terrenos de agostadero de uso común, de la comunidad SAN FRANCISCO XOCHICUAUTLA Y } \\
\text { SU BARRIO LA CONCEPCIÓN, Municipio de Lerma, Estado de México, a favor del organismo } \\
\text { público descentralizado Sistema de Autopistas, Aeropuertos, Servicios Conexos y Auxiliares del } \\
\text { Estado de México, el cual los destinará a la Autopista Toluca-Naucalpan." (DOF, 2015: s/p) }\end{array}$ \\
\hline 2016 & $\begin{array}{l}\text { El } 11 \text { de abril de } 2016 \text { personal de la empresa Teya S.A. de C.V. acompañado de policías municipales } \\
\text { y estatales reiniciaron los trabajos de construcción de la carretera y, como primeras actividades, } \\
\text { demolieron la casa de uno de los activistas en contra del proyecto y un campamento de resistencia, lo } \\
\text { cual fue denunciado por varios medios de comunicación y el Gobierno del Estado de México reaccionó } \\
\text { diciendo que se instalarían mesas de diálogo para atender el tema. } \\
\text { El } 11 \text { de mayo de } 2016 \text { la Comisión Interamericana de Derechos Humanos solicitó al Gobierno del } \\
\text { Estado de México la adopción de medidas cautelares para salvaguardar la integridad física de los } \\
\text { actores que han protagonizado la resistencia al proyecto carretero, pidiendo además que se le informara } \\
\text { de los actos emprendidos para tal fin. } \\
\text { El } 9 \text { de diciembre de } 2016 \text { la Comisión Nacional de los Derechos Humanos emitió la Recomendación } \\
56 / 2016 \text { en la que señala que "los actos que motivaron la emisión de la convocatoria de licitación } \\
\text { pública constituyen una violación a los derechos humanos de las comunidades indígenas otomíes (San } \\
\text { Francisco Xochicuautla y su barrio la Concepción, San Lorenzo Huitzizilapan y Santa Cruz Ayotuzco) } \\
\text { ya que el SAASCAEM por ser la autoridad responsable de la obra estaba obligada a investigar, antes } \\
\text { de emitir la convocatoria de licitación y su resolución, si había comunidades indígenas susceptibles de } \\
\text { sufrir un daño derivado del trazo carretero Toluca Naucalpan, toda vez que es la única manera para que } \\
\text { en caso de que existan, se garantice de manera efectiva los derechos a la consulta previa" (CNDH, } \\
\text { 2016: 70-71)". }\end{array}$ \\
\hline
\end{tabular}

Fuente: elaboración propia con base en trabajo de campo y documental

habilitan ciertas capacidades prefigurativas colectivas como parte del enfrentamiento con el capital" (Tishler y Navarro, 2011: 72). 
Leyva César, M. y Arriaga Ornelas, J.L. La defensa del territorio de San Franciso Xochicuauutla, México, como una forma contenciosa de la diferencia. Derecho y Ciencias Sociales. Noviembre 2019 - Abril 2020 N $^{\circ} 22$. Pgs 144 - 166. ISNN 1852-2971 Instituto de Cultura Jurídica y Maestría en Sociología Jurídica. FCJ y S. UNLP

\section{Emergencia de una forma contenciosa de la diferencia}

Desde las primeros eventos y hasta la fecha ha transcurrido más de una década. La carretera no se ha podido concluir, a pesar de que en varios de sus tramos hay granavanceque la autoridad ha reportado públicamente. ${ }^{7}$ Durante la aproximación etnográfica a la comunidad (ya estando en curso el conflicto) se pudo documentar que los pobladores emplearon la identidad indígena como principal argumento jurídico y político; en tanto que la defensa del territorio y los recursos naturales fue erigida como causa central de su lucha. Igualmente se pudo conocer las diferentes estrategias empleadas y las diferentes arenas en las que han elevado al nivel contencioso su diferenciay son estos:

a) La celebración de asambleas comunitarias bajo la modalidad de "usos y costumbres" (reconocida por el Artículo 2 de la Constitución Política de los Estados Unidos Mexicanos), sobre todo al inicio del conflicto.

b) La conformación del Frente de Pueblos Indígenas en Defensa de la Madre Tierra (FPIDMT), así como la recuperación del Consejo Supremo Otomí (CSO) para constituirlos como interlocutores con el gobierno y otras instancias.

c) El juicio agrario iniciado a partir de su solicitud ante el Comisariado de Bienes Comunales de Xochicuautla y al Registro Agrario Nacional para declarar la nulidad de la Asamblea en la cual se aprobó el proyecto de construcción de la carretera, pero dondel el FPIDMT argumentó que no había quorum para la toma de decisiones. Este juicio lo ganaron mediante sentencia definitiva del 15 de mayo de 2014.

d) Las denuncias presentadas ante la Procuraduría General de la República por los árboles que talaron trabajadores de la empresa (apoyados por la policía estatal) para reanudar los trabajos de construcción de la carretera, a pesar del juicio agrario que habían ganado. Las denuncias fueron por la probable comisión de los delitos de desacato a una sentencia judicial y daños ambientales.

e) Las denuncias presentadas ante la Procuraduría Federal de Protección al Ambiente en el Estado de México por la tala ilegal de árboles, así como la destrucción del suelo vegetal y manantiales de la comunidad. Señalaron como responsables a la empresa Autovan y sus trabajadores.

\footnotetext{
${ }^{7}$ El sitio web oficial de la Secretaría de Infraestructura del Gobierno del Estado de México reporta ese avance y se pueden consultar detalles en esta liga: http://saascaem.edomex.gob.mx/toluca-naucalpan
} 
Leyva César, M. y Arriaga Ornelas, J.L. La defensa del territorio de San Franciso Xochicuauutla, México, como una forma contenciosa de la diferencia. Derecho y Ciencias Sociales. Noviembre 2019 - Abril $2020 \mathrm{~N}^{\circ} 22$. Pgs 144 - 166. ISNN 1852-2971 Instituto de Cultura

Jurídica y Maestría en Sociología Jurídica. FCJ y S. UNLP

f) La queja presentada ante la Comisión Nacional de los Derechos Humanos por violaciones a sus derechos colectivos a ser consultados para la realización del proyecto, así como violaciones a derechos humanos de varias personas durante los operativos policiales en la localidad.

g) La solicitud hecha ante la Comisión Interamericana de Derechos Humanos para que interviniera por considerar que estaban en riesgo varios de sus derechos inalienables como comunidad indígena. La solicitud fue aceptada y la Comisión se pronunció dándoles la razón y solicitando medidas cautelares al Gobierno del Estado de México.

h) La solicitud de Amparo de la Justicia Federal en contra de la planeación, licitación, adjudicación y construcción de la carretera por considerar que viola sus derechos a la libre determinación, al territorio, a la integridad cultural, al agua y a la consulta libre previa e informada. El Amparo le fue concedido a la comunidad por fallas procedimientales en el proceso de consulta por parte de la autoridad.

i) Los varios juicios de Amparo promovidos contra el decreto expropiatorio emitido por el Presidente de la República para permitir que los trabajos de construcción de la carretera continuaran y en el cual se aseguraba que la comunidad había sido consultada. El Amparo de la justicia federal les fue concedido y el Tribunal ordenó la suspensión del acto reclamado, por considerar que la consulta había sido inválida.

j) El FPIDMT y el CSOdurante años se estuvieron movilizando a través de marchas y plantones, denunciado públicamente cada uno de los hechos, convocando a la prensa, buscando interlocución con otros actores sociales y organizando eventos como la "Primera Cumbre de los Pueblos Originarios de la Zona Protegida Otomí-Mexica", convocada para "exigir un alto a la destrucción y las amenazas en contra de la naturaleza y su cultura", a la cual se dieron cita cientos de activistas, colectivos y representantes de organizaciones indígenas y campesinas (Peña, 2016, s/p).

Como puede apreciarse, todo este accionar lo que hace es emplear "el recurso" que les permite el orden jurídico vigente (la Constitución federal, la local, las leyes en materia de derechos y cultura indígena, los tratados internacionales firmados por México, entre otros) para antagonizar con aquellos grupos cuya vocación por obtener ganancias económicas (legitimada por el Estado y el discurso del desarrollo y el crecimiento económico) trastoca lo que ellos consideran su herencia cultural. La decisión de hacer valer la diferencia cultural por parte de la comunidad de 
Leyva César, M. y Arriaga Ornelas, J.L. La defensa del territorio de San Franciso Xochicuauutla, México, como una forma contenciosa de la diferencia. Derecho y Ciencias Sociales. Noviembre 2019 - Abril 2020 N $^{\circ} 22$. Pgs 144 - 166. ISNN 1852-2971 Instituto de Cultura Jurídica y Maestría en Sociología Jurídica. FCJ y S. UNLP

Xochicuautla desmiente la pretensión liberal histórica de que en México hubiera una sola nación, una sola cultura, un solo horizonte. En cambio, devuelve para la discusión el tema de la diferencia; pero si bien lo hace valer en el campo del Derecho positivo (los actos ya enlistados) su vitalidad emana de las nociones de justicia de los pueblos indígenas y su jurisprudencia comunitaria en cuestiones culturales y territoriales. En el caso de la defensa del territorio y la cultura la institucionalidad interna de estas comunidades se muestra como activa promotora de la lucha.

La noción "formas contenciosas de la diferencia" plantea la coexistencia en paralelo de múltiples diferencias culturales que no se funden pacíficamente, sino que antagonizan o se complementan. Cada una se reproduce a sí misma desde la profundidad del pasado y se relaciona con las otras de forma contenciosa (Brighenti y Gago, 2017: 71). En el caso documentado, las acciones jurídicas emprendidas por el FPIDMT y el CSO resultaron exitosas para su causa debido a que el Gobierno en sus diferentes niveles omitió consultar a la comunidad sobre el proyecto antes de emprenderlo. Como el derecho a la consulta libre, previa, informada y adecuada culturalmente está reconocido por la Constitución y los tratados internacionales firmados por México en materia de derechos indígenas, no había forma de que se declararan legales sus actos en este proyecto carretero.

Además, en el terreno político, las autoridades procedieron en todo momento negando la existencia de la comunidad indígena. Implementaron operativos policiales para buscar que los trabajos continuaran, se buscó romper la cohesión de la comunidad y hasta se entregó dinero a muchas personas buscando romper la resistencia al proyecto carretero.

Lo que quedó evidenciado con el actuar jurídico-político del gobierno fue la pervivencia de las dinámicas propias de los procesos coloniales, modernizadores, civilizatorios o de mestizaje e hibridación, porque estos últimos encierran la perenne búsqueda de la mismidad y no el diálogo multicultural; una mismidad que todo el tiempo persigue a la alteridad (Skliar, 2002).

La simetría liberal moderna -todo el Estado es de derecho y todo el derecho es del Estado- es una de las grandes innovaciones de la modernidad occidental. Es también una simetría muy problemática, no solamente porque desconoce toda la diversidad de derechos no estatales existentes en las sociedades, sino también porque afirma la autonomía del derecho con relación a lo político en el mismo proceso que hace depender su validez del Estado. (De Sousa, 2010:106) 
Leyva César, M. y Arriaga Ornelas, J.L. La defensa del territorio de San Franciso Xochicuauutla, México, como una forma contenciosa de la diferencia. Derecho y Ciencias Sociales. Noviembre 2019 - Abril 2020 N $^{\circ} 22$. Pgs 144 - 166. ISNN 1852-2971 Instituto de Cultura Jurídica y Maestría en Sociología Jurídica. FCJ y S. UNLP

La resistencia de la comunidad de Xochicuautla hace visible la diferencia, la existencia de derechos no estatales $\mathrm{y}$, además, hace volver al terreno de la política (del acuerdo, de la construcción del orden social) los actos jurídicos, rompiendo esa pretendía simetría de la que habla De Sousa.

Precisamente en los actos jurídicos que han tenido lugar a lo largo de este conflicto resulta interesante ver cómo las comunidades pasan por distintos estatus jurídicos, pues al principio, en el año 2006, en la licitación para el proyecto carretero no se les menciona siquiera, "como si no existieran". Es el espacio físico el que se concibe como materia importante, no las personas: la autoridad buscaba legalizar la propiedad del terreno (comprando o expropiando), hacer el trazo, talar los árboles existentes y asignar la obra para que se construyera la autopista. Pero paulatinamente este grupo de personas va reclamando reconocimiento a su existencia al presentar denuncias, quejas, al movilizarse, al llamar a la opinión pública a la defensa de su territorio; así, es hasta años después cuando en el Decreto Expropiatorio del Presidente de la República se reconoce: a "la Comunidad San Francisco Xochicuautla y su Barrio La Concepción (como) una comunidad indígena" (DOF,2015:s/p).

A la luz de la evidencia empírica recabada en este trabajo de investigación, este reconocimiento jurídico parece el resultado de la emergencia contenciosa de la comunidad indígena otomí oponiéndose al proyecto, porque a través de las acciones jurídicas, políticas y de movilización que los integrantes de la misma emprendieron, llevaron a las autoridades de distinto tipo a reconocer "que existe" la comunidad, que es indígena y que le asisten derechos. Ello lo constatan los juicios Agrario y de Amparoganados por la comunidad, la Recomendación de la Comisión Nacional de los Derechos Humanos, el pronunciamiento de la Comisión Interamericana de Derechos Humanos y hasta el Decreto Expropiatorio emitido por el Presidente de la República donde se reconoce la existencia de la comunidad. Y no sólo se da ese reconocimiento en el discurso, sino que las autoridades se ven precisadas a a atenderles, a recibir sus quejas, sus denuncias, a concederles el amparo de la Justicia Federal e incluso a "consultarles" su parecer para la realización del proyecto (lo cual ocurrió hasta el año 2015 y con severas críticas por el modo de realizar el ejercicio de consulta).

En el caso de la comunidad de Xochicuautla, la narrativa comunitaria y cultural (que pudo conocerse mediante el trabajo de campo realizado en la comunidad durante varias etapas de 
Leyva César, M. y Arriaga Ornelas, J.L. La defensa del territorio de San Franciso Xochicuauutla, México, como una forma contenciosa de la diferencia. Derecho y Ciencias Sociales. Noviembre 2019 - Abril 2020 N $^{\circ} 22$. Pgs 144 - 166. ISNN 1852-2971 Instituto de Cultura Jurídica y Maestría en Sociología Jurídica. FCJ y S. UNLP

desarrollo del conflicto) se entrelaza con la memoria de lucha, la cosmovisión y la lengua otomí. De este crisol serecuperaron valiosos materiales para hacerlos valer en la arena jurídica, como los documentos de antigüedad, el uso de la lengua, la presencia de tradiciones y costumbres, que eran reconocidas de iure pero no de facto. Y, finalmente, dentro de los amparos y recursos legales "ganados" por la comunidad, se les ha reconocido como sujeto de derechos colectivos, culturales y territoriales.

Cabe subrayar que aún cuando constitucionalmente los pueblos y comunidades indígenas en México tienen un reconocimiento jurídico, que se vuelve un recurso ante un conflicto en el que ellos tienen derecho a conocer, opinar y tomar parte de las decisiones que cualquier autoridad tome en relación con ellos, el proceso que detonó el conflicto omitió este derecho, negando de algún modo la existencia de estas comunidades y su legítimo interés en conservar sus tierras y el hábitat de la zona. Encontraste, es la actuación contenciosa de la comunidad la que finalmente consiguió que representantes de los gobiernos federal, estatal y municipal se sentaran a dialogar con ellos en mesas de trabajo donde se les escuchó y se tomaron diversos acuerdos para reparar daños, detener los trabajos, realizar estudios de distinto tipo y, en pocas palabras, conceder que ellos tienen derechos sobre ese territorio en el que ancestralmente han habitado. Situaciones de este tipo ponen "al descubierto que la mayoría de los Estados modernos se crearon (y actúan) sin respetar las formaciones culturales nacionales o étnicas y, en la generalidad de los casos, violentándolos. En otras palabras, la vieja afirmación de que a un Estado corresponde una nación y que esta se integra por un solo pueblo, ha resultado falsa con el paso del tiempo" (Lopez Barcenas, 2011: 28).

Todo lo anterior confirma varias cosas que se han planteado desde el inicio de este artículo. Primero, se ha constatado la existencia de una materia no resuelta de manera definitiva en México: la diferencia. Segundo, ha resultado evidente que la forma en que actualmente está regulado el conflicto que representa la diferencia, ofreció a los habitantes de Xochicuautla echar mano del recurso jurídico para hacer valer sus argumentos. Tercero, es comprobable que las decisiones político-jurídicas de las autoridades constitucionales involucradas en el conflicto han tenido que transigir pasando de una etapa en la que se niega incluso la existencia misma de la comunidad indígena, a amparar sus derechos y obligar a la negociación, la consulta y el diálogo con los integrantes de la misma. Esto es precisamente lo que logran las "formas contenciosas de 
Leyva César, M. y Arriaga Ornelas, J.L. La defensa del territorio de San Franciso Xochicuauutla, México, como una forma contenciosa de la diferencia. Derecho y Ciencias Sociales. Noviembre 2019 - Abril $2020 \mathrm{~N}^{\circ} 22$. Pgs 144 - 166. ISNN 1852-2971 Instituto de Cultura Jurídica y Maestría en Sociología Jurídica. FCJ y S. UNLP

la diferencia": hacer posible el diálogo, el reconocimiento del otro en su ser y en su saber, como apunta De Sousa Santos:

"la interculturalidad no resulta de un acto voluntarista de arrepentimiento histórico de quienes tienen el privilegio de hacer. Es más bien el resultado de un acto político consensuado entre grupos étnico-culturales muy distintos con un pasado histórico de relaciones, que a pesar de su inherente violencia, abre en al presente coyuntura, una ventana de oportunidad para un futuro diferente. Por esta razón, en el marco de la plurinacionalidad, la interculturalidad, solamente se realiza como democracia intercultural(de Sousa Santos, 2011:118).

\section{Conclusiones}

El conflicto entre la comunidad de Xochicuautla y el Estado por la construcción de una carretera privada que partiría en dos su territorio ancestral puede incluirse dentro de las luchas socioambientales que han venido reproduciéndose en varias partes de América Latina (Sámano, 2017). El hecho de que durante más de una década se haya podido detener la obra y contener el embate sobre las reservas ecológicas del lugar, debe sumarse a las experiencias compartidas entre los implicados en la lucha -no sólo jurídica sino política y cultural- y son partes de un rompecabezas que se descifra y se arma usando enfoques críticos y propositivos para acompañar y aprender de las luchas indígenas y populares. En este tipo de conflictos hay un espacio para lo jurídico, pero este espacio nunca debe entenderse escindido del terreno de la política, que es la arena de diálogo y acuerdo donde deben caber múltiples voces. Por eso es que la noción "forma contenciosa de la diferencia" resulta fértil, porque no es sólo la expresión de un alegato jurídico por cierto derecho o bien que haya sido afectado, sino es la puesta en marcha del antagonismo que encierra la diferencia y del que deben salir mejores formas de regularlo.

Dentro de las lecciones que deja el conflicto revisado en este textodestaca la aportación que la comunidad ha hecho para nutrir al Derecho y buscar nuevas formas de regular las relaciones humanas, de la manera más justa posible. Los precedentes que sientan estas luchas y las formas de organización y emergencia contenciosa pueden ser captadas con una mirada distinta, de "retaguardia". 8 También el legado queda como una experiencia insertaen la memoria de los pueblos, el derecho indígena e incluso en la jurisprudencia del derecho positivo.

\footnotetext{
${ }^{8}$ Propuesta de Boaventura de Sousa Santos: “Trabajos teóricos que acompañan muy de cerca la labor transformadora de los movimientos sociales, cuestionándola, comparándola sincrónica y diacrónicamente, ampliando simbólicamente su dimensión mediante articulaciones, traducciones, alianzas con otros movimientos. Es más un
} 
Leyva César, M. y Arriaga Ornelas, J.L. La defensa del territorio de San Franciso Xochicuauutla, México, como una forma contenciosa de la diferencia. Derecho y Ciencias Sociales. Noviembre 2019 - Abril 2020 N $^{\circ} 22$. Pgs 144 - 166. ISNN 1852-2971 Instituto de Cultura Jurídica y Maestría en Sociología Jurídica. FCJ y S. UNLP

\section{Referencias}

Argumedo, A. (2009). Los silencios y las voces en América Latina. Notas sobre el pensamiento nacional y popular. Buenos Aires: Ediciones del Pensamiento Nacional.

Bataillon, C. (2008). Corona urbana alrededor de la Zona Metropolitana de la Ciudad de México. En Delgado, Javier (Coordinador). La urbanización difusa de la Ciudad de México Otras miradas sobre un espacio antiguo. México: UNAM, pp. 23-42.

Berruecos, L. A. H. (2009). Max Gluckman, las teorías antropológicas sobre el conflicto y la escuela de Manchester. El Cotidiano, 153, 97-113.

Bonfil, G. (1995). El concepto de indio en América: una categoría de la situación colonial.Obras escogidas, México: INI-INAH, vol. 1, 105-124.

Brighenti, M. \&Gago, V. (2017). La hipótesis del mestizaje en América Latina: del multiculturalismo neoliberal a las formas contenciosas de la diferencia. Mora, 23(1), 53-75. Recuperado el 27 de enero de 2018 de: http://www.scielo.org.ar/scielo.php?script=sci_arttext\&pid=S1853001X2017000100004\&ln $\mathrm{g}=\mathrm{es} \& \mathrm{t} \operatorname{lng}=\mathrm{en}$

CNDH (2016).Recomendación 56/2016. Recuperado el 20 de enero de 2018 de: http://www.cndh.org.mx/sites/all/doc/Recomendaciones/2016/Rec_2016_056.pdf

De Sousa, B. (2010). Decolonizar el saber, reinventar el poder. Montevideo: Trilce.

De Sousa, B. (2011). La refundación del Estado en América Latina. La Paz: CLACSO

Diario Oficial de la Federación (DOF) (2015). Decreto por el que se expropia por causa de utilidad pública una superficie de 37-93-86 hectáreas de agostadero de uso común, de la comunidad San Francisco Xochicuautla y su barrio La Concepción, Municipio de Lerma, Edo. deMéx. Secretaría de Gobernación: México. Recuperado el 2 de enero de 2018 de: http://dof.gob.mx/nota detalle.php?codigo=5399973\&fecha=09/07/2015, enero de 2017 .

Dougnac, A. (1994). Manual de derecho indiano. México: UNAM.

Fritzpatrick, P. (1992). The mythology of modern law.London: Routledge.

González, A. (1997). Dos visiones extranjeras sobre el indígena mexicano. Jicotencal (1826) y Xicotencal, príncipe americano (1831). Sábado, suplemento de unomasuno, 1047, 2-3.

Gros, H. (2002) "El constitucionalismo latinoamericano y la codificación en el siglo XIX", Anuario Iberoamericano de Justicia constitucional, núm. 6, ener/dec 2002.

Ibarra, A. C. (2012). Independencia, Reforma, Revolución, ¿y los indios qué?.Estudios de historia moderna y contemporánea de México, (44), 210-214. Recuperado el 30 de enero de 2018 de: http://www.scielo.org.mx/scielo.php?script=sci_arttext\&pid=S018526202012000200010\&lng=es\&tlng=es

INEGI. (2011). Censo de Población y Vivienda 2010(Informe nacional y estatales), México. Recuperado el24 de diciembre de 2017 de: http://www.censo2010.org.mx

trabajo de artesanía y menos un trabajo de arquitectura. Más un trabajo de testigo implicado y menos de liderazgo clarividente. Aproximaciones de lo que es nuevo para unos y muy viejo para otros" (De Sousa, 2010: 36). 
Leyva César, M. y Arriaga Ornelas, J.L. La defensa del territorio de San Franciso Xochicuauutla, México, como una forma contenciosa de la diferencia. Derecho y Ciencias Sociales. Noviembre 2019 - Abril 2020 N $^{\circ} 22$. Pgs 144 - 166. ISNN 1852-2971 Instituto de Cultura

Jurídica y Maestría en Sociología Jurídica. FCJ y S. UNLP

Hale, C. (1972). El liberalismo mexicano en la época de Mora, 1821-1853. México: Siglo XXI Editores.

Kelsen, H. (2009). Teoría Pura del derecho. Buenos Aires: Eudeba.

Krotz, E. (ed.) (2002). Antropología jurídica: perspectivas socioculturales en el estudio del derecho. Barcelona: Anthropos / Universidad Autónoma Metropolitana-Iztapalapa.

Kubli-García, F. (2006). Pasado, presente y futuro de los derechos indígenas en México. En González, N. (coord.) Estudios jurídicos en homenaje a Marta Morineau. México: UNAM.

López-Bárcenas, F. (2016). Los movimientos indígenas en México: rostros y caminos. El Cotidiano, 200, 60-75.

Lopez-Barcenas, F. (2011). Los derechos de los pueblos Indígenas y el desarrollo rural. México: Poder Legislativo LX Legislatura

López y Rivas, G. (2002). Las autonomías indígenas. en González, J. (coord.) Constitución y derechos indigenas. Serie Doctrinas Jurídicas, 92, México: UNAM

Mignolo, W. (2005). La Idea de América Latina: la herida colonial y la opción decolonial, Barcelona: Gedisa.

Montemayor, C. (2010). Los pueblos indígenas de México hoy. México: Editorial Planeta Mexicana.

Peña, A. (2016). Xochicuautla, historia de un pueblo en resistencia. Somos el medio. Recuperado de http://www.somoselmedio.org/article/xochicuautla-historia-de-un-pueblo-en-resistencia.

Pérez, L. (2007). Tridimensión cósmica otomí. Aportes al conocimiento de su cultura. México: Universidad Autónoma Chapingo/Plaza y Valdés.

Radcliffe-Brown, A. (2010). Prefacio en Fortes, M. y Evans-Pritchard, E. (Edit.) Sistemas Políticos Africanos. México: CIESAS/UAM/UIA.

Ramírez, I. y Arriaga, J. L. (2011). La imposibilidad del multiculturalismo en una nación multicultural. Culturales, 7(14), 87-124. Recuperado el 30 de enero de 2018 de: http://www.scielo.org.mx/scielo.php?script=sci_arttext\&pid=S1870$11912011000200005 \& \operatorname{lng}=\mathrm{es} \& \operatorname{tlng}=\mathrm{es}$.

Sámano, M. (2017). Movimientos de resistencia campesina e indígena contra los megaproyectos y el modelo extractivista. El Cotidiano,201, 7-16.

Sierra, M. T. (1996). Antropología jurídica y derechos indígenas: problemas y perspectivas, en Dimensión Antropológica, vol. 8, septiembre-diciembre, 1996, pp. 55-90.Recuperado de: http://www.dimensionantropologica.inah.gob.mx/?p=1439

Skliar, C. (2002).Alteridades y pedagogías:... ¿Y si el otro no estuviera ahi?.Educ. Soc. [online], (23)79, 85-123. Recuperado el 8 de noviembre de 2017 de: http://dx.doi.org/10.1590/S0101-73302002000300007.

Stavenhagen, R. (1988). Derecho Indígena y Derechos Humanos en América Latina. México: El Colegio de México e Instituto Interamericano de Derecho Humanos.

Stavenhagen, R. (2010). Los pueblos originarios: el debate necesario. México: CLACSO. 
Stavenhagen, R. (2013). La Política Indigenista del Estado Mexicano y los Pueblos Indígenas en el Siglo XX. En Baronnet, Bruno y Tapia Medardo (Coord.). Educación e Interculturalidad: política y políticas. Cuernavaca: CRIM-UNAM, 23-48.

Tischler, S. \& Navarro, M. (2011). Tiempo y memoria en las luchas socioambientales en México.Desacatos, 37, 67-80.

Uriarte, A. (2013). El cambio institucional en la administración pública en México y Sinaloa. México: INAP.

Velasco, Ambrosio (2013).Miguel León Portilla. Dos siglos de injusticia. Revista de la Universidad de México,114, 69-72.

Wolkmer, A. y Mánica, S. (2017). Refundación de la teoría constitucional Latinoamericana: Pluralidad y descolonización. Derechos y Libertades: revista de filosofía del derecho y derechos humanos, n. 37, pp. 31-50.

Yrigoyen, R. (2012) El horizonte del constitucionalismo pluralista: del multiculturalismo a la descolonización, en César Rodríguez-Garavito (coord.), El Derecho en América Latina. Un Mapa para el Pensamiento Jurídico del Siglo XXI. Buenos Aires: Siglo XXI, pp. 139-159.

Zibechi,R.. (2014). El Estado de excepción como paradigma político del extractivismo.Composto, C. y Navarro, M. (comp.), Territorios en disputa (pp.76-89) México: Tierra Ediciones. $1^{\circ}$ Edición.

Red Latina sin fronteras. Recuperado el 3 de enero de 2018 de: https://redlatinasinfronteras.wordpress.com/2016/08/23/el-estado-de-excepcion-comoparadigma-politico-del-extractivismo/\#8230 